This is a pre-publication draft of an article to appear in the journal Intercultural Pragmatics. It is possible that some minor infelicities remain, as this article has not been subject to the publisher's final proofing.

\title{
Cross-cultural variation in the perception of impoliteness: A study of impoliteness events reported by students in England, China, Finland, Germany and Turkey ${ }^{1}$
}

\author{
Jonathan Culpeper (Lancaster University, UK), Leyla Marti (Boğaziçi University, Turkey) \\ Meilian Mei (Zhejiang University of Technology, China), Minna Nevala (University of \\ Helsinki, Finland) and Gila Schauer (Lancaster University, UK)
}

\begin{abstract}
This paper investigates cross-cultural variation in the perception of impoliteness. It is based on 500 impoliteness events reported by students in England, China, Finland, Germany and Turkey. The main analytical framework adopted is Spencer-Oatey's (e.g. 2000) "rapport management", covering various types of face as well as sociality rights. We offer some clarifications of this framework, and explain and demonstrate how it can be operationalised for quantitative analysis. In general, it offers a good account of our data, though accommodating ambiguous cases proved to be a major challenge. Our quantitative analysis suggests that three of the five categories of Spencer-Oatey's framework are key ones, namely, quality face, equity rights and association rights. Furthermore, differences between our geographically separated datasets emerge. For example, the England-based data has a preponderance of impoliteness events in which quality face is violated, whereas the Chinabased data has a preponderance where equity rights are violated. We offer some explanations for these differences, relating them where possible to broader cultural issues.
\end{abstract}

Keywords

cross-cultural variation, face, impoliteness, politeness, rights, social norms

\section{Introduction}

Our research investigates English, Chinese, Finnish, German, and Turkish university students' perceptions of what we will refer to as "impoliteness", a term that we will use for any communicative behaviour that is interpreted as offensive. ${ }^{2}$ Our investigation involves a total of 500 diary-type reports of impoliteness events. There is no claim here that we are investigating on-line perceptions, as our methodology involves retrospection and introspection. Instead, we aim to tap into people's understandings of a specific area of language use.

The topic of impoliteness has seen a recent explosion of publishing activity within linguistic pragmatics, including Bousfield (2008), Bousfield and Locher (2008), and Bousfield and Culpeper (2008). However, there is still uncertainty about the notion of impoliteness. Surveying a recent volume of papers on impoliteness, the editors conclude "there is no solid agreement in the chapters as to what 'impoliteness' actually is" (Locher and Bousfield 2008: 3). We will contribute to a central issue in understanding impoliteness, namely, does the concept of face adequately account for all interactions taken to be impolite, or should we be thinking in terms of social norms? The notion of face, of course, is a central concept in the voluminous politeness literature, not least because of its deployment in Brown and Levinson (1987). Why are we examining impoliteness in a cross-cultural perspective? Consider work on politeness. A major impetus for new approaches to politeness, notably the so-called "postmodernist" or "discursive" approaches (e.g. Watts 2003; Locher and Watts 
This is a pre-publication draft of an article to appear in the journal Intercultural Pragmatics. It is possible that some minor infelicities remain, as this article has not been subject to the publisher's final proofing.

2005; Locher 2006), has been the rejection of traditional approaches to politeness in the light of contrary evidence provided by cross-cultural studies. For instance, Brown and Levinson's (1987) notion of face has been criticised for being biased towards an individualistic perspective, and one that cannot adequately account for the group dynamics of at least some "non-Western" cultures (cf. Matsumoto 1988; Gu 1990; Nyowe 1992; Mao 1994). In our view, it makes sense to put notions that may assist in understanding how impoliteness works to the cross-cultural test as a matter of priority, the objective being to let the mechanisms of variation help define impoliteness, rather than let a definition of impoliteness obscure variation.

Culture, of course, is notoriously difficult to define. We will follow the definition of culture proposed by Spencer-Oatey: "Culture is a fuzzy set of attitudes, beliefs, behavioural conventions, and basic assumptions and values that are shared by a group of people, and that influence each member's behaviour and each member's interpretations of the 'meaning' of other people's behaviour" (2000: 4). Cultural stereotypes about things considered impolite abound. For example, groups of people have stereotypes about other groups of people they consider impolite. Culpeper (forthcoming), for example, analyzed the two billion-word Oxford English Corpus, which is dominated by North American data, and retrieved the grammatical subjects of complements containing the word rude. Statistically, the most likely subjects were "doorman", "bouncer", "bartender", "waitress", "waiter", "[New] Yorker", "staff" and "French". Note that the list includes "French", something which hints at a North American stereotype that French people are considered rude, as are the people of the city of New York and people who work in restaurants and bars. Of course, it is not just people who are stereotypically considered rude or impolite. The three infinitival complements of rude (e.g. "it's rude to X") which are statistically most likely are "eavesdrop", "interrupt" and "point". Our point of interest in this paper is not particular impoliteness stereotypes but the evaluative attitudes underlying those stereotypes. For example, it may be that North Americans have an acute sense of rights and obligations in public service contexts, with the consequence that infringements by restaurant or bar staff are especially salient; similarly, they may have an acute sense of rights to personal space, with the consequence that unwarranted intrusions loom large. Of course, we need to be careful here: the previous sentence made a generalization about "North Americans", and such groups of people do not represent a homogenous culture. As Mills (2009) elaborates with respect to impoliteness, the notion of a "national culture" disguises the cultural variation one actually finds within a particular "nation" (a problematic notion in itself), to say nothing of the fact that what one group within a nation may value positively what another may value negatively. Indeed, strictly speaking, our paper does not investigate "cultures", however that is defined, but instead the perceptions of groups of university students based in five different countries. Our main hypothesis is that differences will emerge in the kind of offences reported by the five different groups. Some of those differences are likely to relate to cultural issues, and we will point out possible connections. More specifically, given the cross-cultural research on politeness mentioned above, we hypothesize that our two "non-Western" groups, Turkey and China, diverge from the three "Western" groups, England, Germany and Finland. Certainly in the case of China evidence of less individualistic attitudes in politeness research points to divergence. We will also investigate the hypothesis that the two groups, "Western" / "Non-Western", form relatively unified wholes.

Recent work in politeness studies has seen the rise of "relational" approaches. Christie (2005: 4) points out that three of the five articles constituting the very first edition of the Journal of Politeness Research: Language, Behaviour, Culture stress that politeness is some form of "relational work". Locher and Watts state that "[r]elational work is defined as the 
This is a pre-publication draft of an article to appear in the journal Intercultural Pragmatics. It is possible that some minor infelicities remain, as this article has not been subject to the publisher's final proofing.

work people invest in negotiating their relationships in interaction" (2008: 78). Whether one uses the term "relational work" (Locher and Watts 2005), "relational practice" (Holmes and Schnurr 2005) or "rapport management" (Spencer-Oatey 2000), they all have in common a central focus on interpersonal relations, rather than, as with traditional models of politeness, a central focus on the individual performing "politeness", which is then correlated with interpersonal relations as variables. Also, and importantly for us, impolite behaviour is included within the scope of relational work, rather than presented as a simple dichotomy with politeness.

An important part of our paper will relate to Spencer-Oatey's "rapport management" (e.g. 2000, 2002, 2005, 2007, 2008). We selected this particular relational approach because it is without doubt the most detailed. Furthermore, it also was developed so that is could account for data pertaining to a variety of cultures (cf. 2008: 13). However, the full up-take of Spencer-Oatey's framework by other researchers has been slight, and as far as impoliteness is concerned virtually non-existent. Culpeper (2005) notes that Spencer-Oatey's categories could be used to organise impoliteness strategies, and Cashman (2006) puts this more fully into action, but neither focus on impoliteness perceptions. In particular, no study seems to have followed up Spencer-Oatey (2002), an investigation of politeness perceptions, involving the analysis of informants' reports of conversations which they considered to be "positive". This particular study and methodology inspired our own. However, we cannot simply take Spencer-Oatey's work to contain an "off the shelf" framework ready for application. Most obviously, one cannot assume that what works for politeness also works for impoliteness. Furthermore, it was essential that each member of our team applied the framework in the same way, but it rapidly became clear from an early pilot involving 20 England-based reports that Spencer-Oatey's categories needed further clarification. One of the aims of this paper, then, is to consider carefully how and whether each category of the framework can be operationalized, specifically with respect to data relating to impoliteness perceptions. This aim also explains why in this paper the qualitative discussion of the categories of the framework, as they pertain to our data in Section 3, comes before the quantitative analysis in Section 4 rather than after, as might more usually be the case.

Section 2 of this paper outlines the methodology used in this study. First, it describes the nature of the data, how it was collected and from whom, and, second, it offers a brief summary of Spencer-Oatey's rapport management framework. Section 3 explores that framework in more detail, offers questions that can help operationalize the categories and applies them to impoliteness data. Finally, Section 4 presents a quantitative analysis and discussion of our data.

\section{Methodology}

\subsection{The data and informants}

Whilst impoliteness plays a central role in a number of discourses (Culpeper, Bousfield and Wichman 2003: 1545-1546), naturally-occurring impoliteness is relatively rare in "everyday" contexts, as Leech states (1983: 105), and thus difficult to collect for analysis. ${ }^{3}$

Experimentally induced impoliteness, even assuming that it has a degree of authenticity, is fraught with ethical problems. For example, Lein and Brenneis (1977) used role-play, instructing pairs of children to have an argument about a particular topic. They claim that the resulting data was not artificial because the children became "emotionally involved" (1977: 300). Therein lies the problem that impoliteness involves negative emotional effects, yet 
This is a pre-publication draft of an article to appear in the journal Intercultural Pragmatics. It is possible that some minor infelicities remain, as this article has not been subject to the publisher's final proofing.

research ethics guidelines and committees, for obvious reasons, are wary of such negative effects for informants. ${ }^{4}$

For these reasons, we decided to use what is essentially the diary or field-notes method. Our point of departure here is Spencer-Oatey (2002), for which students were asked to record "rapport sensitive" incidents, that is, "incidents involving social interactions that they [the student informants] found to be particularly noticeable in some way, in terms of their relationship with the other person(s)" (2002: 533-534). Spencer-Oatey's analysis was based on 59 report forms; we will analyse 100 report forms for each of our five countries (i.e. 500 in total). Moreover, we devised a report form that was more detailed and focused than Spencer-Oatey's. In particular, unlike Spencer-Oatey who focuses on events that have either a "particularly positive effect" or a "particularly negative effect", we sought to investigate only the latter. One aspect of our design was to avoid mentioning a label that described the kind of behaviour we are interested in - labels such as "impolite", "rude", "abusive", "aggressive" because the choice of a particular label may have biased our results towards particular behaviours and, moreover, we wished to see what labels the informants would choose (this is the subject of a future study). Thus, we asked informants to report conversations that had a particular effect on them - conversations "in which someone said something to you which made you feel bad (e.g. hurt, offended, embarrassed, humiliated, threatened, put upon, obstructed, ostracised)". A box extending a little less than half a page was provided for reports. Regarding the format of the conversation, informants received the following instruction: "narrate it in your own words, perhaps write it like a play dialogue; we are not looking for a technical description". Underneath the box, they were asked to add contextual detail to their account, and the following prompts were supplied:

(1a) what was actually said, implied or done?

(1b) how was it said, implied or done (e.g. was it something about the pronunciation?)?

(2a) where was it said, implied or done (e.g. in class, on the bus)?

(2b) by whom was it said, implied or done (e.g. what was your relationship with them?)?

(2c) were there were others who heard it too?

(3) what were your reactions (e.g. what did you say, imply or do)?

Informants very rarely worked systematically through this list. The resultant reports of conversations do not have the richness of contextual detail that, say, an ethnographic researcher would record, but they at least afford some insight into what the informants themselves consider contextually relevant.

Unlike Spencer-Oatey, we also asked informants to reflect on their reported conversations in a number of specific ways:

- In order to gauge the gravity of the offence, we posed the question: "How bad did the behaviour in the conversation make you feel at the time it occurred?" Responses were recorded on a 5-point Likert scale. In order to gauge the degree of intentionality ascribed to the behaviour, we posed the question: "Do you think that person meant to make you feel bad?" Responses were recorded on a 5-point Likert scale. ${ }^{5}$

- In order to gain information about resultant emotions, we asked two questions: (1) "We know you felt "bad", but describe your feelings" and (2) "Why did this particular behaviour make you feel bad?" Boxes allowing for a few lines of text were supplied for responses.

- In order to gain information about metalinguistic labels, we asked the question: "How would you describe the behaviour of the person who made you feel bad (how would you label this kind of behaviour?)?" A box allowing for a few lines of text was supplied for responses.

We will not follow up the specifics of each of these reflections individually. Collectively, they often proved to be decisive in helping us classify the kind of offence involved in the reported conversational event. 
This is a pre-publication draft of an article to appear in the journal Intercultural Pragmatics. It is possible that some minor infelicities remain, as this article has not been subject to the publisher's final proofing.

We decided to use undergraduate students as informants in this study. Concentrating on this specific group allowed us to conduct contrasts with students of a similar age and educational background in other countries. Of course, our study is limited by the fact that it is centred in "student culture". It is worth bearing in mind, however, that the bulk of our data involved reports of perceived impoliteness that were not in university contexts. No cultural group is an island unto itself. So, we can reasonably expect many of the perceptions reported by our students also to reflect the cultural knowledge of other groups in that country. We asked informants to supply information about their age and gender, and the membership of each national dataset was determined by a question about the country the informant grew up in. Table 1 quantifies this information.

Table 1. The social profile of our data sets

\begin{tabular}{|l|l|l|l|l|l|l|}
\hline & & English & Chinese & Finnish & German & Turkish \\
\hline \multirow{3}{*}{ Age } & $18-29$ & 98 & 100 & 99 & 99 & 100 \\
\cline { 2 - 7 } & $30-59$ & 2 & 0 & 1 & 1 & 0 \\
\hline \multirow{3}{*}{ Gender } & Female & 79 & 67 & 89 & 73 & 64 \\
\cline { 2 - 7 } & Male & 21 & 33 & 11 & 27 & 36 \\
\hline
\end{tabular}

As can be seen, the profile of each national dataset is broadly similar. It should be noted that the results in this paper are dominated by the perceptions not only of young students but also students who are female.

The final points to be made about our report forms concern their administration and preparation for analysis. At no point were informants told that the research is related to anything to do with "impoliteness". Moreover, informants were not put under pressure to fill it out on the spot. We thought that there would be no guarantee that at any particular moment an individual could remember a particular impoliteness event. A consequence of this is that huge numbers of report forms were administered, in order to achieve 100 complete forms, because students frequently forgot about the form altogether (and ignored reminders). For example in the case of the English data, well over 1,000 report forms were given out. However, the positive side of this is that the completed forms we did receive contained very rich data which gave no indication of having been made up or embellished. ${ }^{6}$ For the nonEngland-based informants, the questionnaires were translated into the participants' native languages. The students completed the questionnaires in their L1, reporting incidents that had happened to them with fellow native speakers of their language (i.e. we did not collect data on cross-cultural incidents between say Chinese and Turkish speakers). All questionnaires were transcribed into electronic files, and then the data were coded according to specific guidelines (see Section 3). All non-English data were also translated into English by the researcher. Note that in this paper all excerpts from the English-based data are given as they were written, with no attempt to "tidy" various spelling, grammatical and other infelicities. The translated data appears in standard written English. Informants' reports are referred to according to their country and informant number (out of 100), e.g. England 2, Turkey 59, China 78.

\subsection{Rapport management: A preliminary summary}

In this section we briefly summarize our analytical framework, rapport management. The following section will return to the categories of that framework in a more critical and expansive manner. Spencer-Oatey writes that "rapport management (the management of harmony-disharmony among people) entails three main interconnected components: the management of face, the management of sociality rights and obligations, and the management 
This is a pre-publication draft of an article to appear in the journal Intercultural Pragmatics. It is possible that some minor infelicities remain, as this article has not been subject to the publisher's final proofing.

of interactional goals" (2008: 13). It is the first two components that offer a way of classifying types of impoliteness offence, and so we will focus on them here. Spencer-Oatey's framework consists of three types of face, and two types of "sociality rights". These are summarised in Table 1 by means of quotations from Spencer-Oatey's work.

\section{Table 1. Categories in the rapport management framework}

\section{Face \\ defined with reference to Goffman (1967: 5): "the positive social value a person effectively claims for himself $[$ sic $]$ by the line others assume he has taken during a particular contact" (2008: 13)}

\section{Sociality rights}

defined as the "fundamental

social entitlements that a person effectively claims for him/herself in his/her interactions with others" (2008: 13)

Quality face
(related to the self as an individual): "We have a fundamental desire for people
to evaluate us positively in terms of our personal qualities, e.g. our confidence,
abilities, appearance etc." (2002: 540)
Relational face
(related to the self in relationship with others): "[s]ometimes there can also be a
relational application; for example, being a talented leader and/or a kind-
hearted teacher entails a relational component that is intrinsic to the evaluation"
(2008: 15$)$
Social identity face
(related to the self as a group member): "We have a fundamental desire for
people to acknowledge and uphold our social identities or roles" (2002: 540$)$;
"[social identity face involves] any group that a person is a member of and is
concerned about. This can include small groups like one's family, and larger
groups like one's ethnic group, religious group or nationality group"
(2005:106).
Equity rights:
"We have a fundamental belief that we are entitled to personal consideration
from others, so that we are treated fairly: that we are not unduly imposed upon,
that we are not unfairly ordered about and that we are not taken advantage of or
exploited" (2008: 16 )
Association rights:
"We have a fundamental belief that we are entitled to social involvement with
others, in keeping with the type of relationship that we have with them." (2008:
16 )

Although Spencer-Oatey's rapport management framework has not been extensively used, we note that it has been employed in a few recently published studies. Spencer-Oatey (2007) and Spencer-Oatey and Xing (2008) analyzed encounters between delegates of a British company and a delegation of Chinese businessmen who were hosted by the British company. The researchers found that both cross-cultural differences in how introductions in business meetings were handled and different views regarding obligations towards the Chinese visitors led to unintended violations of the Chinese businessmen's relational face, as well as violations of their sociality rights. The studies also highlighted the importance of data collection following impoliteness incidents, as data gathered in this way can help raise interlocutors' awareness of different cultural expectations and can thus assist in preventing face threats in cross-cultural communication. Spencer-Oatey's framework has also been successfully deployed in monolingual investigations. Garcia (2010) examined the use of facesupporting strategies in sympathy expressing interactions amongst Peruvian Spanish speakers, while Ho (2010) investigated which strategies two heads of English departments in Hong Kong used in email exchanges with their teachings staff. Garcia found that interlocutors expressing sympathy to relatives of a recently deceased person used strategies that attended to the relative's association rights, such as offering comfort, and also their social identity face by praising the interlocutor. Ho's investigation showed that the heads of the English department also employed strategies that attended to their teachers' social identity face and their associations rights when communicating with them by email. For example, one of the heads 
This is a pre-publication draft of an article to appear in the journal Intercultural Pragmatics. It is possible that some minor infelicities remain, as this article has not been subject to the publisher's final proofing.

used expressions that attended to their subordinates' equity rights by "giving the subordinates the option not to perform the act [...] and in so doing, she constructed a personal identity for herself as being understanding and considerate" (Ho 2010: 2259).

\section{Rapport management: Elaboration and operationalization in the context of impoliteness data}

As we saw in the previous sub-section, Spencer-Oatey's understanding of face follows that of Goffman (1967). A fairly distinctive aspect of Spencer-Oatey's account of face is that she proposes three sub-categories, quality, relational and social identity (three categories of very similar definition can also be found in Domenici and Littlejohn 2006: 6, 13). The inspiration for this comes from social psychological discussions of identity. More specifically, SpencerOatey (2007: 641) cites Brewer and Gardner (1996: 84), who distinguish an individual level of self-representation where we find the "personal self", an interpersonal level where we find the "relational self", and group level where we find the "collective self". In fact, an increasing number of studies in the field of social psychology have elaborated these distinctions. Sedikides and Brewer (2001), for example, is an entire edited collection devoted to distinctions between these levels of self-representation. Spencer-Oatey also notes that the communication studies theorist Hecht (e.g. 1993) makes similar distinctions. These distinctions will emerge more sharply in our discussion below of each sub-categories of face.

The essence of sociality rights (and obligations) is that people expect that others should do or not do certain things in certain contexts (cf. Spencer-Oatey 2005: 98-100; 2007: 651-653). The basis of these expectations could be semi-legal, associated with a particular role, or simply just a social convention that has developed on the basis of what normally happens (Spencer-Oatey 2008: 15). When people conflict with such rights, there is often a sense of injustice, immorality or at least a lack of fair consideration. Social norms, rights and obligations are discussed in the social psychology literature, and often in reference to aggression or competitive social interactions (see, for example, Mummendey and Otten 2001: 334). Sociality rights are not considered face issues, "in that an infringement of sociality rights may simply lead to annoyance or irritation, rather than to a sense of face threat or loss (although it is possible, of course, that both will occur)" (2002: 541). Spencer-Oatey (2007: $625)$ provides the following illustration: a friend who tries to force one to do something or who ignores you, may make you feel irritated or annoyed. But she goes on to say that sometimes such treatment may go further and make you feel that you are not valued by him/her, and hence be face threatening. Clearly, "our face claims and face sensitivities are closely bound up with our sense of sociality rights and obligations" (Spencer-Oatey 2007: $625)$, although there are times when one or the other may be foregrounded, as our examples below will illustrate.

We constructed questions of this kind for all of the categories we examined in our data as a way of clarifying the categories and assisting in their application. When deciding whether face is involved in a potentially impolite interaction the question to be asked is: does the interaction evoke an understanding that something counters a positive attribute (or attributes) which a participant claims not only to have but to be assumed by other participant(s) as having? Note that there are negative counterparts of the face-related questions. In the case of the question above it would be: does the interaction evoke an understanding that something affirms a negative attribute (or attributes) which a participant claims not only not to have but to be assumed by other participant(s) as not having? When deciding whether sociality rights are involved in a potentially impolite interaction the question to be asked is: does the 
This is a pre-publication draft of an article to appear in the journal Intercultural Pragmatics. It is possible that some minor infelicities remain, as this article has not been subject to the publisher's final proofing.

interaction evoke an understanding that something counters a state of affairs which a participant considers to be considerate and just?

In the remainder of this section, we elaborate on each of the five sub-categories (i.e. the right-hand column of Table 1), and explore their application to our impoliteness data.

Quality face

Spencer-Oatey (2002: 540) defines quality face as follows:

We have a fundamental desire for people to evaluate us positively in terms of our personal qualities; e.g. our competence, abilities, appearance etc. Quality face is concerned with the value that we effectively claim for ourselves in terms of such personal qualities as these, and so is closely associated with our sense of personal self-esteem.

This, of course, echoes Goffman's (1967) definition of face, as given above. Quality face also clearly overlaps with Brown and Levinson's (1987) notion of positive face. What is distinctive about Quality face is that the values are based on the individual (cf. Spencer-Oatey 2005: 106-107; 2008: 14), that is, the values pertain to the constellation of personal attributes that distinguish a person as a unique individual in their social world. When deciding whether quality face is involved in a potentially impolite interaction, the question to be asked is: does the interaction evoke an understanding that something counters positive values which a participant claims not only to have as a specific individual but to be assumed by other participant(s) as having? Below is an example from our data. The informant describes the event in a couple of sentences; she uses numbers to organise her contextual information:

\section{Turkey 89}

When travelling by bus, a stupid person sitting next to me asked me a question. I did not know the answer, s/he said 'ignorant'.

1. I did not say anything and thought that I was right.

2. It is of course bad not to know the answer for a person coming to a good school like this.

3. S/he said that it was a joke but it was too late. I swore/cursed silently.

In this example, the target is ascribed the negative personal value "ignorant". Her quality face is violated (she acknowledges that being ignorant is "bad") and she takes offence (evidence for which is perhaps the silent cursing).

One specific type of offence that we placed under quality face but has a somewhat problematic fit concerns the use of taboo words or topics. This is illustrated by the following example:

\section{England 19}

On the beach in the South of England with my family. My dad has bought me a snorkel set but the sea is freezing and I don't use it.

'Come on son, be brave.' <said quite jokingly>

'I am'.

'your not gonna do much snorkelling there'.<said quite jokingly>

(After attempting to get in the sea).

'Dad its freezing ... I don't want to!' <being stubburn>

'Oh don't be a wimp'.

'No dad I'm not going in'. <being stuburn> (said as I walked up the beach).

'Well we might as well throw it in the $\mathrm{f}^{* *}$ king sea then'! <stress on $\mathrm{f}^{* *}$ king $>$

The informant comments "I wasn't used to my dad swearing so I was quite shocked" (there is no mention in his reflection of the fact that his father also referred to him as a "wimp"). Brown and Levinson (1987: 67) treat "irreverence" and the "mention of taboos" as a positive 
This is a pre-publication draft of an article to appear in the journal Intercultural Pragmatics. It is possible that some minor infelicities remain, as this article has not been subject to the publisher's final proofing.

face issue, on the basis that "S indicates that he doesn't value H's values and doesn't fear H's fears". "H's values" suggests the hearer's individual values, and hence this is an issue of quality face. Thus, in the above example, and in tune with how Goffman defines face, the father demonstrates that his son's values regarding the avoidance of taboo language are not upheld. Support for the idea that the use of taboo language or talk about taboo topics may in some contexts involve threat to face can be found in the fact that its usage may cause embarrassment, and embarrassment is a symptom of face loss. Goffman noted the emotional consequences of face loss:

If events establish a face for him [sic] that is better than he might have expected, he is likely to 'feel good'; if his ordinary expectations are not filled, one expects that he will 'feel bad' or 'feel hurt'. (1967: 6)

He may become embarrassed and chagrined; he may become shamefaced (1967: 8)

Cupach and Metts's (1994) book on facework contains a chapter on "embarrassing predicaments". Drawing on Buss (1980), they note five types of event that commonly cause embarrassment, and the first listed is "impropriety (e.g., improper dress, dirty talk)" (1994: 19), something which clearly can involve taboo behaviour. The informant of the above example describes himself as feeling "mostly embarrassed". However, taboo usage does not simply map on to quality face; social conventions or sociality rights govern the usage of taboo language. In the above example, one could argue that the convention of not "swearing" in the presence of his son is violated. We treated all such examples cautiously. ${ }^{7}$ In fact, all primarily involved quality face, as there was evidence of individual values not being upheld and consequent self-oriented emotions, such as embarrassment.

\section{Social identity face}

Spencer-Oatey (2002: 540) defines social identity face as follows:

We have a fundamental desire for people to acknowledge and uphold our social identities or roles, e.g. as group leader, valued customer, close friend. Social identity face is concerned with the value that we effectively claim for ourselves in terms of social or group roles, and is closely associated with our sense of public worth.

In contrast with quality face, social identity face is based on the group or the collective (cf. Spencer-Oatey 2005: 106-107; 2008: 14). As Turner, Hogg, Oakes, Reicher and Wetherell (1987: 50) remarked over twenty years ago, the collective self involves a "shift towards the perception of self as an interchangeable exemplar of some social category and away from the perception of self as a unique person". A problem with the detail of Spencer-Oatey's (2002) definition is that her examples include social roles. Social roles, such as teacher-student, parent-child or friends, involve specific relational bonds between people with attendant social functions (e.g. a teacher teaches, a student learns, etc.), rather than mere membership of a social collective. In fact, social roles overlap with relational face, a subcategory of face which Spencer-Oatey added in later publications (e.g. 2007, 2008) and which we will more fully discuss below. Interestingly, social roles seem to be downplayed by Spencer-Oatey in later publications when social identity face is defined, as in the following: 
This is a pre-publication draft of an article to appear in the journal Intercultural Pragmatics. It is possible that some minor infelicities remain, as this article has not been subject to the publisher's final proofing.

The attributes that people are face-sensitive about can apply to the person as an individual and also to the group or community that the person belongs to and/or identifies with. [...] A person could regard him/herself as a talented individual (e.g. a talented artist), and s/he could regard the small group or community that s/he belongs to as being talented (e.g. a talented family or a talented work team or sports team). (2008: 15)

Actually, we think that roles can span either social identity face or relational face, depending on the focus. Let us illustrate with the role of teachers. If a teacher says that they get offended by comments from a family member about teachers having a soft life because they supposedly get such long holidays, that would be a critical comment about all members of the group - it is an issue of social identity face. However, if a teacher says that they get offended by comments from a family member that they are unable to communicate with their own students, that would be a critical comment about a role relationship - an issue of relational face. The label teacher defines the group according to a relational function, and so it spans both types of face.

When deciding whether social identity face specifically is involved in a potentially impolite interaction the question to be asked is: does the interaction evoke an understanding that something counters positive values which a participant claims not only to have in common with all other members in a particular group, but to be assumed by other participant( $(s)$ as having? Here is an example from our data:

\section{England 23}

We were playing American football and one of my teammates went to tackle whoever had the ball. The person with the ball dived to the ground to avoid taking the hit. My teammate then returned to me to moan about him. "it's because he's a vegetarian, fucking veggie", he said. I then replied "I'm a vegetarian". He then started to apologise prefucely, but I told him to get out of my face! This was said on the field where we train and there must have been 4 or 5 people at least that could have heard. Obviously I was insulted as he stereotyped all vegetarians as being wimps.

Here, it is implied that a particular group, vegetarians, are shy of aggressive contact and cowardly. Although the informant is not the target of the disparaging remark, he takes offence because he is a member of that group - his social identity face is violated. Here is another example, this time from the Finnish dataset:

\section{Finland 16}

At home; the two of us: (I can't remember the exact words)

Boyfriend: What can women become when they get older? Like when a man can become 'charming'?

I: I guess a woman could be 'beautiful' or 'elegant'.

Boyfriend: Name one older woman who's beautiful.

I: (Pointing at a picture of Helen Mirren). And Susan Sarandon.

Boyfriend: (Disagrees)

I: You don't think an older woman can be beautiful?

Boyfriend: On average, older men and women tend to lose their looks, but some men are charming when they're old.

(I fell silent and the conversation ended as we started watching TV). I felt that my boyfriend was implying that older women can't be beautiful. I was annoyed and a bit depressed about it but then I forgot the whole conversation.

The informant is not part of the group of "older women" but is destined to become so. Thus, the impolite implication is that, as the informant writes, "my boyfriend would no longer consider me beautiful when I get older". 
This is a pre-publication draft of an article to appear in the journal Intercultural Pragmatics. It is possible that some minor infelicities remain, as this article has not been subject to the publisher's final proofing.

\section{Relational face}

Spencer-Oatey's (2007) addition of this subcategory reflects the three levels of representation argued for in fairly recent social psychological work (e.g. Brewer and Gardner 1996;

Sedikides and Brewer 2001). Of relational face, Spencer-Oatey writes: "Sometimes there can also be a relational application; for example, being a talented leader and/or a kind-hearted teacher entails a relational component that is intrinsic to the evaluation" (2008: 15; our emphasis). Note that "leader" and "teacher" are social roles, and, as we pointed out in our discussion of social identity face, social roles involve specific relationships. Of course, all social phenomena are relational in general terms. Spencer-Oatey (2007: 647) clarifies what she specifically means by relational: "the relationship between the participants (e.g. distancecloseness, equality-inequality, perceptions of role rights and obligations), and the ways in which this relationship is managed or negotiated". However, where we disagree with the above definition is in the inclusion of the words "rights and obligations". Including these words invites unwanted, at least from a methodological point of view, overlap with sociality rights which we will discuss below. In order to tighten up this category, it is worth considering the social psychological literature. In a comprehensive discussion of the relational self, Chen, Boucher and Tapias write that it "reflects who a person is in relation to his or her significant others" (2006: 153). The inclusion of "significant others" in a definition of relational face is a useful way of distinguishing it from social identity face. ${ }^{8}$ Chen, Boucher and Tapias (2006: 160) elaborate on this distinction:

Like relational selves, then, collective selves entail some degree of connection with others. However, whereas relational selves involve a connection with known, identifiable significant other or group of significant others, collective selves designate connections with individuals whose identities may not be known $[\ldots]$

Collective selves generally involve shared features amongst in-group members, rather than unique relations between individuals (Chen, Boucher and Tapias 2006: 161). When deciding whether relational face is involved in a potentially impolite interaction the question to be asked is: does the interaction evoke an understanding that something counters positive values about the relations which a participant claims not only to have with a significant other or others but to be assumed by that/ those significant other(s) and/ or other participant(s) as having? Examples would include someone being thought of as a good friend, a valued family member or a good teacher. Some of the clearest examples of relational face occur in our Chinese data, for instance (the informant provides no contextualizing detail):

\section{China 6}

Lunch time, I saw her immediately after I went to the cafeteria. I told her ideas for some activities for our class. I intended to collect some suggestions from my classmates by telling them the activities ahead of the schedule. I was shocked at her answer. She rejected the ideas loudly with a tone of ordering in front of all the people in the cafeteria. Despite explaining to her softly and humbly, she rejected them more disrespectfully than before, paying no attention to my good manner. I was greatly annoyed because my classmates all respected me and I had never come across situations like that before. I began to think about all that I had done and what I should do in the future. I felt very puzzled.

Revealingly, this informant comments thus on this interaction: "My good intention was rejected coldly and rudely. That was a great threat and puzzle to a leader of a class" (our emphasis). What troubled this informant is that her relational value as a leader of her classmates, a group of significant others, had been threatened. Here is another example, this time from the German dataset:

\section{Germany 67}


This is a pre-publication draft of an article to appear in the journal Intercultural Pragmatics. It is possible that some minor infelicities remain, as this article has not been subject to the publisher's final proofing.

My best friend, with whom I had been close friends since the fifth grade, had had an abortion. After the abortion, she was very poorly and rarely attended school. One day, my tutor and her trainee approached me to talk to me about my friend's absence and her health. On the one hand I felt interrogated. On the other, they made me look silly. Both teachers made it clear to me that they thought that I did not really know what was going on with my friend by the way they asked the questions and also by their reactions to my answers. They gave me the impression that I was "a bad friend".

In this case, the informant takes offence at the implication that she is a "bad" best friend, that is to say, her relations with a significant other (her "best friend") are negatively valued.

\section{Sociality rights: Equity}

Although both the subcategories equity rights and association rights are defined in some detail in Spencer-Oatey (2002: 540-541), some refinements were added in later work. SpencerOatey (2005: 100) defines equity as follows:

[...] people have a fundamental belief that they are entitled to personal consideration from others and to be treated fairly; in other words, that they are not unduly imposed upon, that they are not unfairly ordered about, and that they are not taken advantage of or exploited. This principle [...] seems to have three components: cost-benefit considerations (the principle that people should not be exploited or disadvantaged), fairness and reciprocity (the belief that costs and benefits should be "fair" and kept roughly in balance), and autonomy-control (the belief that people should not be unduly controlled or imposed upon).

Brown and Levinson's (1987) notion of negative face overlaps primarily with the notion of equity rights, in as far as they relate to matters of imposition and costs/benefits. The notion of equity has been long established in the social psychology literature. For example, regarding equity, Adams (1965) put forward the idea that each member of a community is entitled to a quantity of resources or rewards that are in proportion to his or her investment or contribution. This overlaps to an extent with the notion of "distributive justice" (see Tedeschi and Felson 1994: 218-219). Regarding reciprocity, an element included in Spencer-Oatey's definition of equity (see the definition above), Gouldner (1960) put forward the idea that behaviour, prosocial, antisocial or of some other kind, should be matched (cf. Spencer-Oatey's equity idea of keeping thing roughly in balance). When deciding whether equity rights are involved in a potentially impolite interaction the question to be asked is: does the interaction evoke an understanding that something counters a state of affairs in which a participant considers that they are not unduly exploited, disadvantaged, unfairly dealt with, controlled or imposed upon? Below is a brief example of equity rights being violated from our data:

\section{China 52}

In a cafeteria I greeted my classmate. But he did not respond.

The absence of a returned greeting, the preferred response in this adjacency pair, violates reciprocity rights and thereby causes offence. Note that equity rights, as all sociality rights, relate to people's sense of fairness, and hence have a moral dimension.

\section{Sociality rights: Association}

Spencer-Oatey (2005: 100) defines association as follows:

[...] people have a fundamental belief that they are entitled to an association with others that is in keeping with the type of relationship that they have with them. This principle [...] seems to have three components: involvement (the principle that people should have appropriate amount and types of "activity" involvement with others), empathy (the belief that people should share appropriate concerns, 
This is a pre-publication draft of an article to appear in the journal Intercultural Pragmatics. It is possible that some minor infelicities remain, as this article has not been subject to the publisher's final proofing.

feelings and interests with others), and respect (the belief that people should show appropriate amounts of respectfulness for others).

Spencer-Oatey does not make the connection, but there are obvious overlaps here with Goffman's (1967:113-136) discussion of "involvement obligations". In Goffman's own words:

There are many occasions when the individual participant in conversation finds that he and the others are locked together by involvement obligations with respect to it. He comes to feel it is defined as appropriate (and hence even desirable in itself or prudent) to give his main focus of attention to the talk, and to become spontaneously involved in it, while the same time he feels that each of the other participants has the same obligation. Due to the ceremonial order in which his actions are embedded, he may find that any alternate allocation of involvement on his part will be taken as a discourtesy and cast an uncalled-for reflection upon the others, the setting, or himself. (1967: 115)

When deciding whether association rights are involved in a potentially impolite interaction the question to be asked is: does the interaction evoke an understanding that something counters a state of affairs in which a participant considers that they have an appropriate level of behavioural involvement and sharing of concerns, feelings and interests with others, and are accorded an appropriate level of respect? Below is an example from our data (the layout follows what is supplied by the informant):

\section{Germany 97}

1a) A person told me about a grave change in their lives

1b) I felt hurt, because she only told me the truth after such a long time and had talked to several other people before.

And the informant makes the following comment:

I got the impression that the person did not trust me (anymore). I was disappointed not to have been told about what went on when it went on and when I could have helped by giving advice. I felt that we had grown apart from each other a lot, which made me sad.

Clearly, offence was taken because the informant was not granted the level of involvement they considered appropriate. Let us examine another example, this time from the Turkish dataset:

\section{Turkey 7}

Yesterday evening I mentioned on the phone to a close friend of mine about a project that I was preparing for FLED 103 course. I told him/her that I read the things that I wrote myself and the references again and again in the research process when planning and at the writing up stage. I said that after the project was finished I started again to proofread it in order to find a mistake but gave up feeling bored. S/he said that "You acted stupid. There was no need for this" I did not expect words like this from him/her since s/he knew that this assignment was important to me and I felt offended how s/he evaluated my effort to do this project better in such a way.

Of course, one can immediately see aspects of quality face here: "you acted stupid". However, that primary focus of her comments relates to association rights. She did not "expect" such a negative evaluation from a "close friend", given "s/he knew that this assignment was important to me". This is also reinforced in her reflections: "I'm a perfectionist I pay attention to details that others find unnecessary, but people especially those who are close to me should respect this or they should completely ignore it". The key issue for her is disrespectfulness: "This is disrespectfulness towards me and my efforts and I can't stand disrespectfulness". 
This is a pre-publication draft of an article to appear in the journal Intercultural Pragmatics. It is possible that some minor infelicities remain, as this article has not been subject to the publisher's final proofing.

This section has expanded on and clarified issues relating to the categories of SpencerOatey's rapport management. We have shown that each category can capture a different kind of impoliteness offence. The framework is clearly fit for our impoliteness purposes. For each category, we have also proposed a question which researchers can ask themselves in order to establish whether or not a particular impoliteness offence fits a particular category. These were the questions we used to operationalize our quantitative analysis.

\section{A quantification of types of offence in our data}

\subsection{A note on our quantitative method}

Applying Spencer-Oatey's categories to impoliteness events for offence type is difficult, because of ambiguities and indeterminacies. As has been illustrated in the previous section, the major source of evidence guiding our application of the categories was the informants' own reflective commentaries. So, for example, China 6, discussed above, was classified as primarily a matter of relational face because the informant commented that the issue was the fact that her classmates had violated the relationship they had with her as "leader of the class". Cases such as this primarily involving one category were relatively easy to quantify. However, sometimes multiple types of offence are involved in one event. For example, someone who does not pay you the attention you expect given the relationship, a matter of association rights, may also imply they have a low value of your opinions, a matter of quality face (see Germany 97 above, for a similar case). We accommodated such cases by not only recording for each case which category was primarily involved, but also which other categories were involved. This analysis allowed thus to quantify for each of our five datasets (1) the total number of reported events classified as involving offence primarily relating to one particular category, and (2) the total number of reported events classified as involving offence relating to any relevant category.

To help ensure inter-rater reliability of our classifications, all categories were assigned by the researcher responsible for a particular culture, and then checked by the lead author of this paper. Problematic cases were discussed and the evidence reviewed. Where a classification decision could be made (e.g. to treat taboo language as a matter of quality face), it was recorded in a "guide" and circulated amongst all members of the team, so that consistency could be maintained not only across all team members but also over the course of the classification exercise (i.e. decisions made towards the beginning of the exercise could be remembered and followed towards the end of the exercise). With respect to primary offence, where a classification decision could be not be made the case was deemed indeterminate primary offence and only quantified for any relevant category (these represent less than $5 \%$ of any dataset and so in no way impact on the results discussed below).

\subsection{Results}

Figure 1 displays the frequencies of the primary types of perceived offence in impoliteness events across our datasets from England, China, Finland, Germany and Turkey. It allows us to see if there are differences in terms of what primary offence type is involved. Figure 2 displays the frequencies of any relevant type of perceived offence in impoliteness events across our datasets from England, China, Finland, Germany and Turkey. It allows us to see if there are differences in terms of what offence type is involved. 
This is a pre-publication draft of an article to appear in the journal Intercultural Pragmatics. It is possible that some minor infelicities remain, as this article has not been subject to the publisher's final proofing.

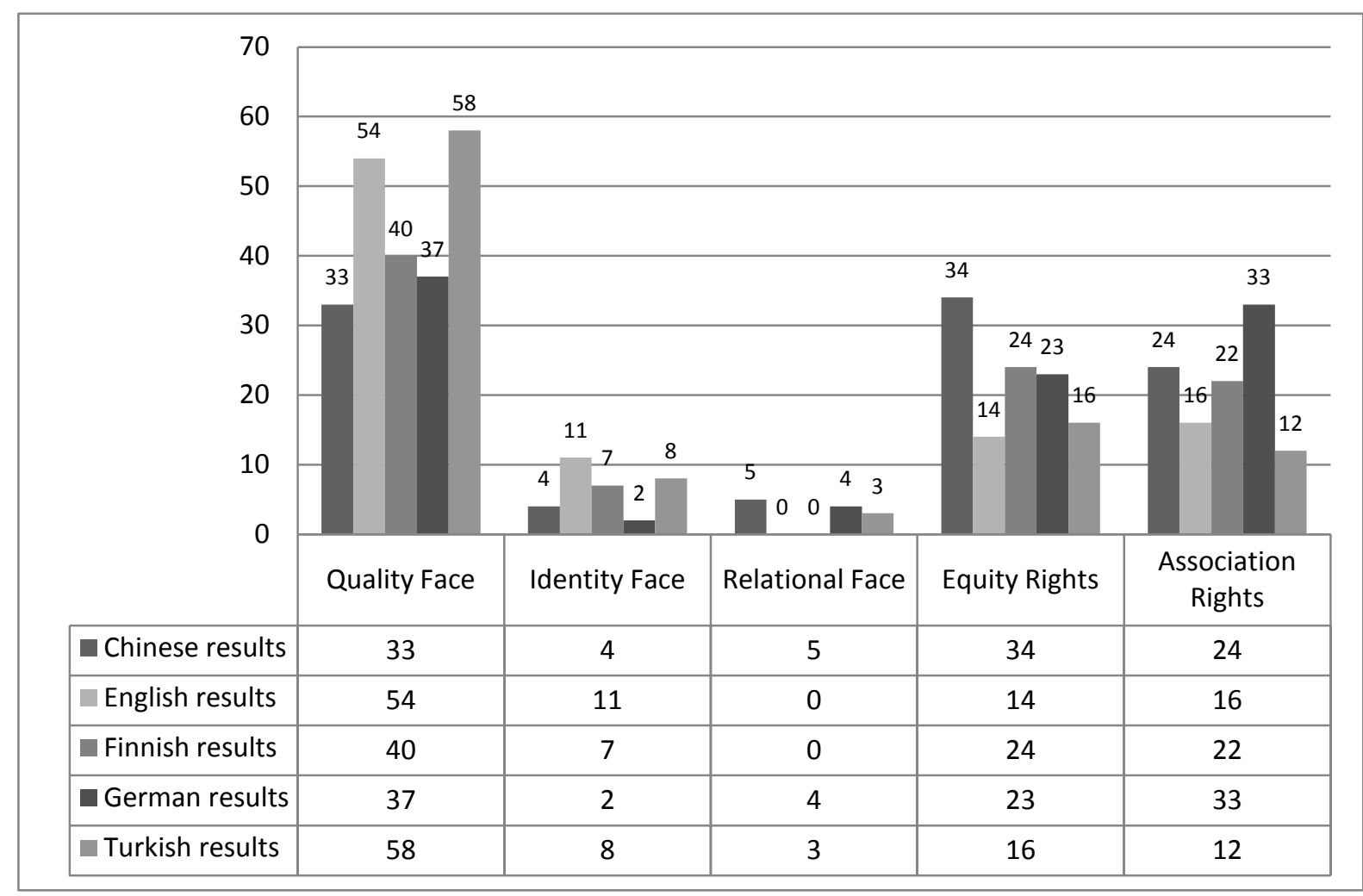

Figure 1. Variation in primary types of perceived offence in impoliteness events across five countries

\begin{tabular}{|c|c|c|c|c|c|}
\hline 90 & & & & & \\
\hline 80 & 77 & & & & \\
\hline 70 & 69 & & & & \\
\hline & & & & & \\
\hline 50 & 47 & & & 46 & 14 \\
\hline 40 & & & & 32 & 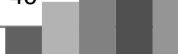 \\
\hline 30 & & & & -1 & -5 \\
\hline 20 & & ${ }^{20} 17$ & & & \\
\hline 10 & & 7 & 5 & & 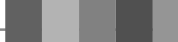 \\
\hline 0 & Quality Fac & Identity Face & Relational Face & Equity Rights & $\begin{array}{c}\text { Association } \\
\text { Rights }\end{array}$ \\
\hline Chinese results & 47 & 7 & 12 & 45 & 40 \\
\hline English results & 77 & 20 & 3 & 41 & 44 \\
\hline Finnish results & 69 & 17 & 2 & 32 & 56 \\
\hline German results & 62 & 6 & 10 & 46 & 64 \\
\hline Turkish results & 78 & 12 & 5 & 44 & 55 \\
\hline
\end{tabular}

Figure 2. Variation in types of perceived offence in impoliteness events across five countries 
This is a pre-publication draft of an article to appear in the journal Intercultural Pragmatics. It is possible that some minor infelicities remain, as this article has not been subject to the publisher's final proofing.

\subsection{Discussion}

We would make the following general observations:

- All the datasets for both primary and any offence type (Figures 1 and 2) featured quality face as the most frequent category, except the German dataset for any type of offence (Figure 2) and Chinese for primary offence (Figure 1). This stands testimony to the power of Goffman's notion of face (Spencer-Oatey's quality face is the closest of her categories to Goffman's notion).

- However, face, of whatever sub-type, is far from being the only relevant category of offence, whether primary or secondary. Equity and Association rights clearly play an important role.

- Together, Quality Face, Equity Rights and Association Rights are by far the most frequently relevant categories: together, they constitute the three big. In contrast, social identity face and relational face are of little consequence.

- There appears to be a pattern of complementary distribution in the primary offence results (Figure 1) (and to a lesser extent the any offence results) for the English and Turkish datasets, such that when quality face is high, sociality rights (i.e. equity and association rights summed) are low, and for the Chinese and German datasets, such that when sociality rights are high, quality face is low. The Finnish dataset bucks this trend with a more balanced weighting).

It is transparent from Figures 1 and 2 that our main hypothesis, i.e. differences will emerge in the kind of offences reported by the five different groups, is confirmed. Regarding the specific offence types, we can make the following observations:

- Regarding quality face, for primary offence there are significant differences amongst the values $\left(X^{2} 17.5\right.$; d.f. $\left.4 ; p<0.002\right)$. The Turkish data had the most instances (closely followed by English), and the Chinese the least. This distribution is also reflected in the any offence data.

- Regarding equity rights, for primary offence there are significant differences amongst the values $\left(X^{2} 13.4\right.$; d.f. $\left.4 ; p .<0.01\right)$. The Chinese data had the most instances and the English the least (preceded by Turkish).

- Regarding association rights, for primary offence there are significant differences amongst the values $\left(X^{2} 14.5\right.$; d.f. $\left.4 ; p .<0.006\right)$. The German data had the most instances and the Turkish the least (preceded closely by English). The German data also had the most instances in the any offence data.

- As mentioned above, the other categories are of minor consequence, though it is interesting to note that social identity face is more important in the English data, and relation face is more important in the Chinese and German data. These distributions are also reflected in the any offence data.

Of course, all of these results need replication and validation from further studies, ideally deploying different yet complimentary methodologies. On the face of it, they offer some intriguing hypotheses and puzzles. Finding quality face to be an important category for the English data was not a surprise, given that that concept (very closely matching Goffman's 1967 definition) has been central in Anglo-Saxon politeness research. But why is it also the most important category of all for the Turkish data? This does not chime with our hypothesis that "Western" groups would diverge from "non-Western". But of course Turkey's status as 
This is a pre-publication draft of an article to appear in the journal Intercultural Pragmatics. It is possible that some minor infelicities remain, as this article has not been subject to the publisher's final proofing.

"non-Western" is questionable. Even in traditional terms, it is considered part of the "near east" as opposed to the "far east", where China is placed. It is also worth noting that Turkey is currently applying to be part of the European Economic Community. Certainly, a notion similar to the concept of face is current in Turkish cultures. For example, yüzsüz means faceless, doesn't feel ashamed; yüz kizartici means causing the face to redden. This does not imply that the notion of face is exactly the same across all cultures or the same as that posited by Goffman. In fact, Ruhi and Işık (2007) point out the importance in Turkey of appealing to people's true, inner selves, rather than simply their public image (á la Goffman). Looking at the students' reports in detail, one difference that emerged concerned the circumstances in which quality face was lost. The Turkish informants often reported that what hurt was the public loss of quality face (one might speculate that this is because of the public exposure and violation of values closer to the true inner self). This was not a feature found in the English data.

The divergence of the Chinese dataset with respect to the prominence of equity rights (see in particular Figure 1) at least partially confirms the "Western" groups diverging from "non-Western" hypothesis. We think that the importance of equity rights found in the Chinese data can be explained in two ways. One is the long-standing influence of Confucianism in Chinese culture, something which other scholars have noted and discussed (e.g. Scollon and Scollon 2001). Liji ["The Book of Ritual"], a collection of ideas of Confucianism, says that $l i$ shang wang lai, wang er bu lai, fei li ye; lai er bu wang, yi fei li ye ["Propriety suggests reciprocity. Not to give out but only to receive, or vice versa, is not propriety"] (Shisanjing zhushu ["Explanations of the Thirteen Lections"]: 1231c). Chinese also culture advocates a reciprocity principle (Hwang 1987; Gu 1990; Spencer-Oatey 2002). This is shown in Chinese expressions like tou tao bao li ["if one gives you a peach, you should requite his favour with a plum"] and di shui zhi en yong yuan xiang bao ["If you have received a drop of beneficence from other people, you should return to them a fountain of beneficence"]. The other possible explanation is related to Chinese family planning policies, according to which families can only have one child. The only child in a family would be regarded as a great treasure by his/her parents and grandparents, and be the centre of attention, accustomed to having his/her desires satisfied. University students, most of whom are the only child in their families, experience a radical change in their set of equity entitlements: they easily get hurt as they experience group norms. Of course, all the explanations offered in this paragraph are generalization that need to be treated with the utmost caution.

The importance of association rights for the German data was something we did not expect. It is a feature that marks it out as very different from the other "Western" groups, England and Finland. One possibility is that this arises because the quality and quantity of friendship relationships tend to be different in Germany-based cultures. Bruckner and Knaup (1993) is a study of women's and men's friendships in a comparative national cross-cultural perspective. They make the following comment about friendship relationships in Germany:

\footnotetext{
While Americans tend to enter into many informal associations of a friendly character, in Germany 'private' activities are limited to a small group of 'selected' and long-standing 'real' friends. Corresponding differences in the average number of friends have been corroborated by Pappi and Melbeck (1988) in their empirical study on core discussion networks in the United States and Germany. (1993: 25)
}

Association violations in the context of a tight network of friendships may have been perceived particularly strongly by the German informants.

In this section, we have not commented much on the Finnish data. This is for the reason that the Finnish frequencies tend towards the average for all categories. 
This is a pre-publication draft of an article to appear in the journal Intercultural Pragmatics. It is possible that some minor infelicities remain, as this article has not been subject to the publisher's final proofing.

\section{Conclusion}

One of the aims of this paper was methodological. With respect to the "rapport management" framework developed by Spencer-Oatey, we have carefully reviewed the nature of the categories, adding clarification where possible (for example, for the category of relational face we emphasized the feature of "significant others"). Given that we wanted to classify our data according to these categories, it was essential that we had a clear understanding of them and how they could be operationalized. One way in which we did this was to propose questions that captured the essence of each category, questions which each researcher could use to help establish if a particular example in their data belonged to a particular category. We also designed our report forms so that informants reflected on their own reports, and these reflections offered us important guidance in categorising the data. The major problem we encountered was ambiguity. Issues of face and sociality rights overlap and are constantly at play in interaction. However, it is frequently the case that some aspects are foregrounded in a particular interaction in relation to others. Our quantification method accommodated these feature, capturing both the primary offence type of an event, if there was one (as indeed there mostly was), and also any relevant offence type.

Overall, we have demonstrated that rapport management is a powerful analytical tool, one that can be applied to cross-cultural variation. Having said that, it should be noted that not all the categories of which it is comprised were equally populated by our data. With regard to face, quality face is overwhelmingly the most important type of face. The aim of our quantitative analysis was to reveal any preferential tendencies for particular offence types amongst our geographically separated student groups; in other words, to reveal whether there is variation in the ways in which different groups of people take offence. Our main hypothesis was that differences would emerge in the kind of offences reported by the five different groups, and indeed they did. We noted the importance of quality face for both the English data and also the Turkish data, although for the Turkish data, we suggested that the circumstances in which quality face was damaged tended to be different, that is, they more often involved the loss of face in public. We accounted for the importance of equity rights in the Chinese data by referring to the influence of Confucianism and possibly the one-child family planning policy. The importance of association rights for the German data may reflect cultural differences in the quality and quantity of friendship relations. Finally, we noted that the Finnish data tended not to be outstanding for any category. We had hypothesized that our two "non-Western" groups, Turkey and China, would diverge from the three "Western" groups, England, Germany and Finland. This was not the case for the Turkish group, something that would fit the idea that its status as "non-Western" is marginal at best. The evidence for the Chinese group diverging was much clearer. The fact that equity rights are so prominent in the Chinese data is consistent with the finding in politeness research that group values are prized more highly than individualistic ones. We had also hypothesized that the two groups "Western" / "Non-Western" would form relatively unified wholes. This was far from the case. Not only were Turkey and China unalike, but the Germany group had a very different distribution of offence types compared with England or Finland.

Of course, we stress yet again that our data contain 100 university undergraduates in each of the five countries. Therefore, we cannot claim to represent the cultural diversity in each country. Similarly, our explanations for the differences in our data are generalizations that would not necessarily hold for all cultural groups in those countries. Nevertheless, undergraduates are not an island unto themselves, and many of the events they reported involved "everyday" non-university contexts. It is not unreasonable to suppose that that some 
This is a pre-publication draft of an article to appear in the journal Intercultural Pragmatics. It is possible that some minor infelicities remain, as this article has not been subject to the publisher's final proofing.

of the attitudes they espoused are cultural attitudes they share more closely with at least some other social groups in their respective countries than with some social groups from other countries. But of course this is where further research in needed.

\section{Acknowledgement}

The lead author's role in this paper has been supported by the U.K.'s Economic and Social Research Council (ESRC) (RES-063-27-0015), awarded to the first author. Some parts of this article are elaborated on in Culpeper (forthcoming). We are indebted to the following people for helping us gather data from their students (in no particular order): Fu Bei (Zhejiang University of Technology), Martin Pütz (Universität Koblenz-Landau); Beatrix Busse (Universität Bern); Roland Kehrein (Philipps Universität Marburg); Tanja Giessler (Philipps Universität Marburg); Hans-Jörg Schmid (Ludwig-Maximilians Universität München); Anke Lüdeling (Humboldt Universität zu Berlin); John Dixon, Andrew Wilson, Eivind Torgersen, Sebastian Hoffman, Kevin Watson, Veronika Koller, Pelham Gore (Lancaster University); Sara Mills (Sheffield Hallam University); Andrew Merrison (York St John University); Amy Wang (Manchester Metropolitan University); Toini Rahtu, Turo Vartiainen, Mari PakkalaWeckström, Marianna Hintikka, Maria Salenius, Juhani Härmä, Päivi Sihvonen (University of Helsinki); Janne Skaffari (University of Turku); Sirpa Leppänen (University of Jyväskylä); Greg Watson (University of Joensuu). A special thank you also goes to Johanna Tanner for her help in analysing the Finnish data. Finally, this paper would not be what it is without the detailed and challenging feedback provided by two referees and, especially, our editor, Pilar Garcés-Conejos Blitvich. We can only apologize if this paper fails to live up to their comments.

${ }^{1}$ This study is the first of a number of papers evolving from the Cross-Cultural Impoliteness Project (CCIP).

${ }^{2}$ All impoliteness-related terms, such as impoliteness, rudeness and verbal abusiveness, have their own particular semantic flavours and pragmatic usages. Of course, one could use a phrase such as "talk that gives offence", although that is not a particularly economic option and results in some clumsy phrasings. One reason for using impoliteness is that it is extremely rare. In the two-billion word Oxford English Corpus, it is used a mere 30 times. It also invites people to make connections with academic work on politeness.

${ }^{3}$ It is difficult to imagine that we could survive in a world in which we more frequently took offence at what people said than we did not. Further evidence for the general relative rarity of genuine impoliteness may also be in the fact that the icons of British English politeness please and thank you occur so much more frequently than possible icons of impoliteness such as cunt and motherfucker (the two British English lexical items considered most offensive in the year 2000, according to Millwood-Hargrave 2000). In the two-billion word OEC (which includes much unregulated, informal discourse from such sources as blogs) the frequencies are: please $(14,627)$, thank you (5,533), cunt (157) and motherfucker (88). Of course, there is no guarantee that all these instances of usage actually involved politeness or impoliteness (some might have been, for example, sarcasm or banter), but, given the huge frequency differentials, there seems to be some support.

${ }^{4}$ For example, the British Association of Applied Linguistics: Recommendations on Good Practice in Applied Linguistics (http://www.baal.org.uk/about_goodpractice_full.pdf) states on page 4 that "Applied linguists should respect the rights, interests, sensitivities, and privacy 
of their informants. It is important to try to anticipate any harmful effects or disruptions to informants' lives and environment, and to avoid any stress, undue intrusion, and real or perceived exploitation."

${ }^{5}$ In order to reduce the possibility of an interaction effect, the intentionality question and rating scale was separated from the gravity of offence question and rating scale and also placed on a different sheet of paper.

${ }^{6}$ Each research collected until they had received the necessary 100 forms for their dataset; thus, they did not collect more than 100 forms and then have to decide which to select. ${ }^{7}$ Of course, taboo language need not involve impoliteness at all, but signal, for example, solidarity in a perfectly acceptable way, given the right context. Such cases are not included in our data because informants only report what they consider impolite.

${ }^{8}$ Spencer-Oatey (2007: 641) does briefly mention "significant others" once in the context of discussing Brewer and Gardner's (1996: 84) understanding of the relational self.

\section{References}

Adams, James S. 1965. Inequity in social exchange. In Leonard Berkowitz (ed.), Advances in experimental social psychology (Volume 2), 267-299. London and New York: Academic Press.

Arundale, Robert. 2006. Face as relational and interactional: A communication framework for research on face, facework, and politeness. Journal of Politeness Research. 2(2). 193-217.

Bousfield, Derek \& Jonathan Culpeper (eds.). 2008. Impoliteness: Eclecticism and diaspora. [Special Issue]. Journal of Politeness Research 4(2).

Bousfield, Derek \& Miriam Locher (eds.). 2008. Impoliteness in language: Studies on its interplay with power in theory and practice. Berlin \& New York: Mouton de Gruyter.

Bousfield, Derek. 2008. Impoliteness in interaction. Philadelphia \& Amsterdam: John Benjamins.

Brewer, Marilynn B. \& Wendi Gardner. 1996. Who is this "we"? Levels of collective identity and self representations. Journal of Personality and Social Psychology. 71(1). 83-93.

Brown, Penelope \& Stephen C. Levinson. 1987. Politeness: Some universals in language usage. Cambridge: Cambridge University Press.

Bruckner, Elke \& Karin Knaup. 1993. Women's and men's friendships in a comparative perspective. European Sociological Review. 9(3). 249-266.

Buss, Arnold H. 1980. Self-consciousness and social anxiety. San Francisco, CA: W. H. Freeman.

Cashman, Holly. 2006. Impoliteness in children's interactions in a Spanish/English bilingual community of practice. Journal of Politeness Research. 2(2). 217-246.

Chen, Serena, Boucher, Helen C. \& Molly Parker Tapias. 2006. The relational self revealed: Integrative conceptualization and implications for interpersonal life. Psychological Bulletin. 132(2). 151-179.

Christie, Chris. 2005. Editorial. Journal of Politeness Research 1 (1). 1-7.

Culpeper, Jonathan, Derek Bousfield \& Anne Wichmann. 2003. Impoliteness revisited: With special reference to dynamic and prosodic aspects. Journal of Pragmatics. 35(10-11). $1545-1579$. 
This is a pre-publication draft of an article to appear in the journal Intercultural Pragmatics. It is possible that some minor infelicities remain, as this article has not been subject to the publisher's final proofing.

Culpeper, Jonathan. 2005. Impoliteness and entertainment in the television quiz show: The Weakest Link. Journal of Politeness Research. 1(1). 35-72.

Culpeper, Jonathan. Forthcoming. Impoliteness: Using language to cause offence. Cambridge: Cambridge University Press.

Cupach, William R. \& Sandra Metts. 1994. Facework. London: Sage.

Domenici, Kathy and Stephen W. Littlejohn. 2006. Facework. London: Sage.

Garcia, Carmen. 2010. 'Cuente conmigo': The expression of sympathy by Peruvian Spanish speakers. Journal of Pragmatics 42. 408-425.

Goffman, Erving. 1967. Interaction ritual. Chicago: Aldine Publishing.

Gouldner, Alvin W. 1960. The norm of reciprocity: A preliminary statement. American Sociological Review. 25(2). 161-178.

$\mathrm{Gu}$, Yueguo. 1990. Politeness phenomena in modern Chinese. Journal of Pragmatics. 14(2). 237-257.

Hecht, Michael L.. 1993. 2002-A research odyssey: Toward the development of a communication theory of identity. Communication Monographs. 60. 76-80.

Ho, Victor. 2010. Constructing identities through request e-mail discourse. Journal of Pragmatics 42. 2253-2261.

Holmes, Janet and Stephanie Schnurr (2005) Politeness, humor and gender in the workplace: Negotiating norms and identifying contestation. Journal of Politeness Research 1(1). 121-149.

Hwang, Kuang-kuo. 1987. Face and favor: The Chinese power game. The American Journal of Sociology. 92(4). 944-974.

Leech, Geoffrey N. 1983. Principles of Pragmatics. London: Longman.

Leech, Geoffrey N.. 2003. Towards an Anatomy of Politeness in Communication. International Journal of Pragmatics. 14. 101-123.

Lein, Laura \& Donald Brenneis. 1978. Children's disputes in three speech communities. Language in Society. 7. 299-323.

Locher, Miriam A. \& Derek Bousfield. 2008. Introduction: Impoliteness and power in language. In Derek Bousfield \& Miriam Locher (eds.), Impoliteness in language: Studies on its interplay with power in theory and in practice, 1-13. Berlin \& New York: Mouton de Gruyter.

Locher, Miriam A. \& Richard J. Watts. 2005. Politeness theory and relational work. Journal of Politeness Research. 1(1). 9-33.

Locher, Miriam A. \& Richard J. Watts. 2008. Relational work and impoliteness: Negotiating norms of linguistic behaviour. In Derek Bousfield \& Miriam A. Locher (eds.) Impoliteness in Language: Studies on its Interplay with Power in Theory and Practice, 77-99. Berlin and New York: Mouton de Gruyter.

Locher, Miriam A. 2006. Polite behavior within relational work: The discursive approach to politeness. Multilingua. 25(3). 249-267.

Mao, LuMing Robert. 1994. Beyond politeness theory: 'Face' revisited and renewed. Journal of Pragmatics. 21(5). 451-486.

Matsumoto, Yoshiko. 1988. Reexamination of the universality of face: politeness phenomena in Japanese. Journal of Pragmatics. 12(4). 403-426.

Mills, Sara. 2009. Impoliteness in a cultural context. Journal of Pragmatics 41. 1047-1060.

Millwood-Hargrave, Andrea. 2000. Delete expletives?: Research undertaken jointly by the Advertising Standards Authority, British Broadcasting Corporation, Broadcasting Standards Commission and the Independent Television Commission. London: ASA, BBC, BSC and ITC. 
This is a pre-publication draft of an article to appear in the journal Intercultural Pragmatics. It is possible that some minor infelicities remain, as this article has not been subject to the publisher's final proofing.

Mummendey, Amélie \& Sabine Otten. 2001. Aggressive behaviour. In Miles Hewstone \& Wolfgang Stroebe (eds.), Introduction to social psychology, 315-340. Oxford: Blackwell.

Nwoye, Onuigbo G. 1992. Linguistic politeness and socio-cultural variations of the notion of face. Journal of Pragmatics. 18(4). 309-328.

Ruhi, Sükriye \& Hale Iş1k. 2007. Conceptualising face and relational work in (im)politeness: Revelations from politeness lexemes and idioms in Turkish. Journal of Pragmatics. 39. 681-711.

Scollon, Ron and Suzanne W. Scollon. 2001. Intercultural Communication: A Discourse Approach ( $2^{\text {nd }}$ edn). Oxford: Blackwell.

Sedikides, Constantine \& Marilynn B. Brewer. 2001. Individual self, relational self, collective self. Philadelphia: Psychological Press.

Shisanjing Zhushu (Qing Ruan Yuan Jiao Keban). 1998. Hangzhou: Zhejiang Guji Chubanshe. [ Explanations of the thirteen lections, The version published under Ruan Yuan's direction in Qing dynasty]. Hangzhou: Zhejiang Ancient Books Publishing House.

Spencer-Oatey, Helen \& Jianyu Xing. 2008. Issues of face in a Chinese Business visit to Britain. In Helen Spencer-Oatey (ed.), Culturally Speaking: Culture, communication and Politeness Theory ( $2^{\text {nd }}$ edn.), 258-273. London: Continuum.

Spencer-Oatey, Helen \& Wenying Jiang. 2003. Explaining cross-cultural pragmatic findings: moving from politeness maxims to sociopragmatic interactional principles (SIPs). Journal of Pragmatics. 35. 1633-1650.

Spencer-Oatey, Helen. 2000. Rapport management: A framework for analysis. In Helen Spencer-Oatey (ed.), Culturally speaking: Managing rapport through talk across cultures, 11-46. London: Continuum.

Spencer-Oatey, Helen. 2002. Managing rapport in talk: Using rapport sensitive incidents to explore the motivational concerns underlying the management of relations. Journal of Pragmatics. 34. 529-545.

Spencer-Oatey, Helen. 2005. (Im)Politeness, face and perceptions of rapport: Unpackaging their bases and interrelationships. Journal of Politeness Research. 1(1). 95-119.

Spencer-Oatey, Helen. 2007. Theories of identity and the analysis of face. Journal of Pragmatics. 39. 639-656.

Spencer-Oatey, Helen. 2008. Culturally speaking: Managing rapport through talk across cultures (2nd. edn.). London: Continuum.

Tedeschi, James T. \& Richard B. Felson. 1994. Violence, Aggression, and Coercive Actions. Washington DC: American Psychological Association.

Turner, John C., Michael Hogg, Penelope Oakes, Stephen Reicher \& Margaret Wetherell. 1987. Rediscovering the social group: A self-categorization theory. Oxford: Blackwell.

Watts, Richard J. 2003. Politeness. Cambridge: Cambridge University Press. 